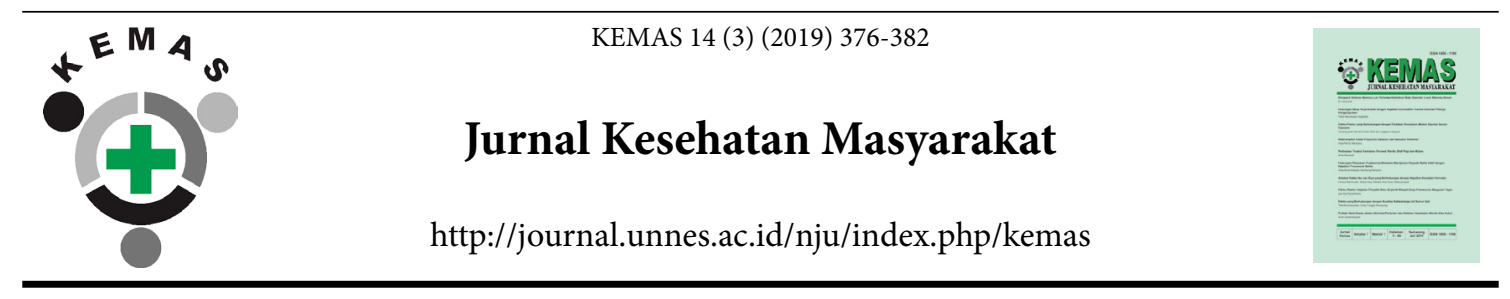

\title{
Indonesia Hospital Cost Analysis: a Micro-Costing Approach
}

\author{
Ragil Setia Dianingati ${ }^{1}$, Arthorn Riewpaiboon ${ }^{2 \bowtie}$, Sitaporn Youngkong ${ }^{2}$ \\ ${ }^{1}$ Department of Pharmacy, Universitas Ngudi Waluyo, Indonesia \\ ${ }^{2}$ Department of Pharmacy, Faculty of Pharmacy, Mahidol University, Thailand
}

\section{Article Info \\ Article History: \\ Submitted February 2018 \\ Accepted February 2018 \\ Published March 2019 \\ Keywords: \\ Unit Cost, \\ Micro-costing Approach, \\ Hospital, Indonesia \\ DOI \\ https://doi.org/10.15294/ \\ kemas.v14i3.1562}

\begin{abstract}
Efforts to develop the financing methods is needed to strengthen the Indonesia's recently implemented universal health coverage system. Hospital cost data is urgently needed to calculate the unit cost of medical services that is important to evaluate the reimbursement rate setting. The most recent approach to calculate unit cost of medical services in hospital is micro-costing approach. This study aimed to perform a unit cost calculation using micro-costing approach in Indonesia's district hospital in June-Dec 2016 from the provider perspective. The costing study followed the standard costing method and financial data were obtained through the hospital financial reports. Some financial data were directly measured since this study used bottom-up approach. This study showed that the unit cost was not relevant with the reference price set up by the government. It could be caused by different cost items and cost objects that had been employed in the study since the government tariff's did not have clear and detailed information about the source of cost calculation. Micro-costing approach was useful as a precise method to calculate unit cost, even though rigorous efforts were needed to complete the data.
\end{abstract}

\section{Introduction}

Although Indonesia has established its universal health coverage system in 2014 the system still requires strengthening efforts. One of the pivotal is to develop financing method that requires information on unit cost of hospital medical services.

Information about the unit cost of medical services will help the decision makers and hospital managers to negotiate the reimbursement rate setting, especially in low and middle-income countries (Chatterjee, Levin, \& Laxminarayan, 2013; Teerawattananon et al., 2016). However, it is undeniable that information about hospital cost is limited in the developing countries (Chatterjee et al., 2013, Javid, Hadian, Ghaderi, Ghaffari, \& Salehi, 2015).
To provide unit cost information, a study to calculate the cost of medical service provision, or often called cost analysis study (WHO, 2013) is needed. Cost analysis study is needed in order to provide meaningful information for policy makers and hospital managers to improve hospital service and manage resources effectively.

There are several methods to calculate the unit cost of medical services, such as average method, micro-costing method, ratio of cost to charge (RCC), and relative value unit (Schulman-Marcus, Prabhakaran, \& Gaziano, 2010). The micro-costing method currently is the most accurate (Riewpaiboon, Malaroje, \& Kongsawatt, 2007) despite requiring a large amount of data, which is time-consuming and costly (Cao et al., 2006; Cao et al., 2006). The 
choice of method and approach used in the calculation of unit cost will affect the result (Riewpaiboon et al., 2007).

District hospital in Indonesia is the first layer after primary health care providers to provide medical services after the establishment of a new referral system according to the Indonesia UHC system. The reference price to provide medical services in district hospital was set by the government (Kementerian Kesehatan Republik Indonesia, 2016). However, there is no study that used standard costing method to calculate the unit cost of district hospital in Indonesia.

Micro-costing method will allow detailed and precise calculation of the unit cost (Yereli, 2009). However, this method consumes a lot of time and cost due to the amount of data needed.

This study aimed to observe the unit cost of laboratory services in a district hospital using micro-costing approach from the provider's perspective to be compared with the reference price.

\section{Methods}

Economic cost analysis of medical services was done using standard cost approach adopted from existing hospital costing manual. This study was designed as retrospective descriptive cost analysis. The study population was public district hospitals in Yogyakarta. Pratama Yogyakarta hospital (45 inpatient beds) was selected by convenience method. Resource used and service provided during June-Dec 2016 were included in the analysis. Field works for data collection was done during July 2017-January 2018. First, the study was designed to calculate the unit cost using provider perspective, and the costing template was developed using Microsoft Excel. The second step was analysing the organizational structure and classifying it as transient and absorbing cost centres. Since the bottom-up approach was used, the absorbing cost centres were all the departments that provide medical services to the patient. Third step was determining the direct cost. Capital cost was calculated using economic approach and allocated using the proportion of equipment usage as well as the material cost was calculated using the proportion of consumed material. The full time

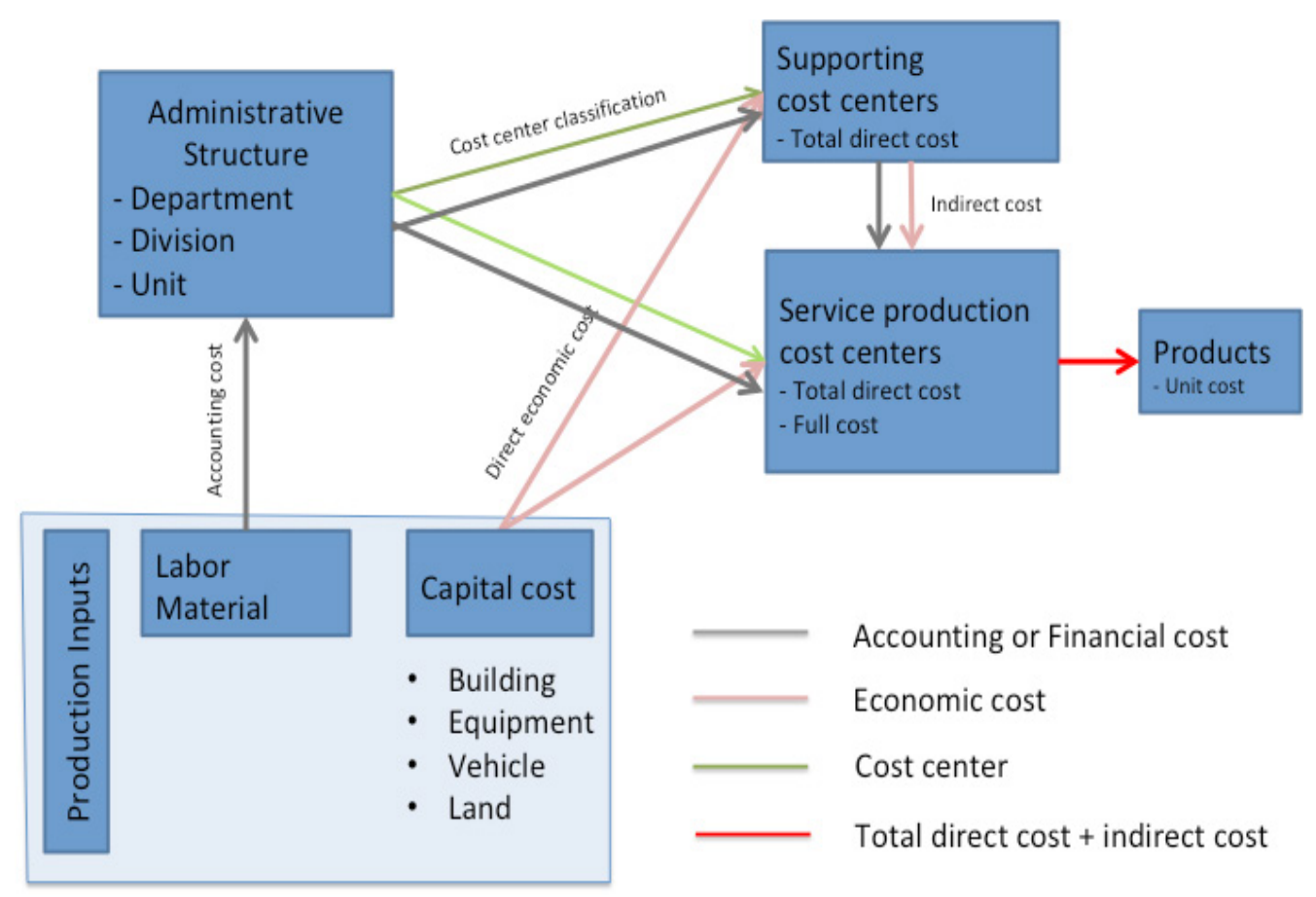

Fig. 1. Standard cost calculation concept and the cost flow 
equivalent system was employed to allocate the proportion of time spent for each cost centre. Labor cost was allocated using the proportion of time spent for the professional to do each service. The total direct cost was allocated to indirect cost using the simultaneous equation method by using mathematical formula in Excel as the fourth step. In the fifth step, the full cost of absorbing cost centers were calculated. The last step, the unit cost of services was calculated using micro-costing method. Due to the time limitation of the research, microcosting approach employed only for laboratory services. All cost were based on Indonesian Rupiah in 2016. Unit cost of the laboratory services were calculated using micro-costing approach, analysed and compared with the reference price using descriptive statistics.

\section{Results and Discussion}

There were 20 hospital departments in Pratama Yogyakarta Hospital that was classified into 10 transient cost centres and 12 absorbing cost centres as shown in Table 1. The special case was inpatient department that classified as 3 absorbing cost centres because in Pratama Yogyakarta Hospital the inpatient department was categorized into 3 sub-departments, inpatient for pediatric, adult and maternal perinatal.

There were 55 lab services at Pratama Yogyakarta Hospital. Full cost of each absorbing cost center was obtained from the calculation. The full cost of lab is IDR $1,917,262,098$, which obtained from IDR 2,164,689 total direct cost and IDR 1,649,164,339 indirect or shared cost. From the calculation, the unit cost of each

Table 1. Hospital Departments that was Classified Into Transient Cost Centre (T) and Absorbing Cost Centre (A)

\begin{tabular}{ll}
\hline Cost center & Code \\
\hline Administration & T1 \\
Planning & T2 \\
Finance & T3 \\
Maintenance & T4 \\
Supply & T5 \\
Sanitation (Waste Management) & T6 \\
Laundry & T7 \\
CSSD & T8 \\
Catering & T9 \\
Medical Record & T10 \\
Pharmacy & A1 \\
Laboratory & A2 \\
Radiology & A3 \\
ER & A4 \\
CSI & A5 \\
HCU & A6 \\
Mortuary & A7 \\
Dentistry & A8 \\
OPD & A9 \\
IPD Pediatric & A10 \\
IPD Adult & A11 \\
IPD Maternal and Perinatal & A12 \\
\hline
\end{tabular}


Table 2. Unit Cost Result From Micro-Costing Method and Reference Price and the Percent Difference

\begin{tabular}{|c|c|c|c|c|}
\hline No & Test & Unit Cost & Reference Price & \% Difference \\
\hline 1 & ABO Blood Group & 91,761 & 10,000 & $818 \%$ \\
\hline 2 & $\mathrm{ABO}+\mathrm{Rh}$ Blood Group & 160,258 & 13,500 & $1087 \%$ \\
\hline 3 & Albumin & 182,581 & 25,000 & $630 \%$ \\
\hline 4 & Amphetamine & 182,581 & 35,000 & $422 \%$ \\
\hline 5 & Antal Eritrocyte & 366,088 & 8,000 & $4476 \%$ \\
\hline 6 & Antal Leukocyte & 321,298 & 8,000 & $3916 \%$ \\
\hline 7 & Antal Trombocyte & 456,293 & 8,600 & $5206 \%$ \\
\hline 8 & Anti HBsAg & 261,246 & 37,000 & $606 \%$ \\
\hline 9 & Anti HCN & 182,581 & 49,500 & $269 \%$ \\
\hline 10 & Bleeding Time & 182,581 & 9,600 & $1802 \%$ \\
\hline 11 & BTA Sputum & 607,274 & 20,000 & $2936 \%$ \\
\hline 12 & Clotting Time & 273,871 & 9,600 & $2753 \%$ \\
\hline 13 & Cocaine & 182,581 & 35,000 & $422 \%$ \\
\hline 14 & Complete Blood Test & 273,871 & 40,900 & $570 \%$ \\
\hline 15 & Creatinin & 322,800 & 20,000 & $1514 \%$ \\
\hline 16 & DGNI (Gram Coloring) & 182,581 & 20,000 & $813 \%$ \\
\hline 17 & Direct Bilirubin & 182,581 & 20,000 & $813 \%$ \\
\hline 18 & Erythrocyte Sedimentation Rate & 409,434 & 8,000 & $5018 \%$ \\
\hline 19 & Globulin & 182,581 & 25,000 & $630 \%$ \\
\hline 20 & Glucose & 296,519 & 15,500 & $1813 \%$ \\
\hline 21 & Haematocrit & 370,879 & 8,000 & $4536 \%$ \\
\hline 22 & Haemoglobin & 199,455 & 8,000 & $2393 \%$ \\
\hline 23 & HAV & 182,581 & 81,440 & $124 \%$ \\
\hline 24 & HBsAG & 245,513 & 37,000 & $564 \%$ \\
\hline 25 & HDL & 670,576 & 20,000 & $3253 \%$ \\
\hline 26 & HIV & 509,619 & 120,000 & $325 \%$ \\
\hline 27 & IgG dan IgM Dengue & 182,581 & 130,000 & $40 \%$ \\
\hline 28 & Indirect Bilirubin & 182,581 & 20,000 & $813 \%$ \\
\hline 29 & LDL & 806,698 & 65,500 & $1132 \%$ \\
\hline 30 & Leptospira & 182,581 & 35,000 & $422 \%$ \\
\hline 31 & Leucocyte Differential Count & 182,581 & 10,000 & $1726 \%$ \\
\hline
\end{tabular}


Table 2. (Continue)

\begin{tabular}{|c|c|c|c|c|}
\hline No & Test & Unit Cost & Reference Price & \% Difference \\
\hline 32 & Malaria & 449,866 & 20,000 & $2149 \%$ \\
\hline 33 & Marijuana & 182,581 & 35,000 & $422 \%$ \\
\hline 34 & NS1Ag & 182,581 & 25,000 & $630 \%$ \\
\hline 35 & Opiate/Morphine & 182,581 & 35,000 & $422 \%$ \\
\hline 36 & Peripheral Blood Morphology & 182,581 & 69,000 & $165 \%$ \\
\hline 37 & Pregnancy Test & 105,157 & 8,000 & $1214 \%$ \\
\hline 38 & Protein & 157,747 & 8,000 & $1872 \%$ \\
\hline 39 & Reduction & 157,747 & 8,000 & $1872 \%$ \\
\hline 40 & Reticulocyte & 182,581 & 8,600 & $2023 \%$ \\
\hline 41 & Rh Blood Group & 91,526 & 7,500 & $1120 \%$ \\
\hline 42 & Routine Blood Test & 573,074 & 50,000 & $1046 \%$ \\
\hline 43 & Routine Faeces & 242,389 & 15,000 & $1516 \%$ \\
\hline 44 & $\begin{array}{l}\text { Routine Urine (Chemistry } \\
\text { and Sediment) }\end{array}$ & 322,512 & 20,000 & $1513 \%$ \\
\hline 45 & Urethral Secretion & 182,581 & 20,000 & $813 \%$ \\
\hline 46 & Vaginal Secretion & 182,581 & 35,000 & $422 \%$ \\
\hline 47 & SGOT & 377,361 & 20,000 & $1787 \%$ \\
\hline 48 & SGPT & 355,149 & 20,000 & $1676 \%$ \\
\hline 49 & Total Bilirubin & 182,581 & 20,000 & $813 \%$ \\
\hline 50 & Total Cholesterol & 420,231 & 18,000 & $2235 \%$ \\
\hline 51 & Total Protein & 182,581 & 25,000 & $630 \%$ \\
\hline 52 & Triglyceride & 517,177 & 18,000 & $2773 \%$ \\
\hline 53 & Tubex Tifoid & 273,871 & 145,500 & $88 \%$ \\
\hline 54 & Urea & 358,733 & 20,000 & $1694 \%$ \\
\hline 55 & Uric Acid & 417,684 & 25,000 & $1571 \%$ \\
\hline
\end{tabular}

laboratory services was shown in Table 2 . The unit cost of each laboratory services varied from IDR 91,526-IDR 806,698. The lowest was $\mathrm{ABO}$ blood group test and the highest was lowdensity lipid (LDL) test.

The result from unit cost calculation was compared to the one set by Yogyakarta government. The laboratory service costs were higher than the reference price. The percentage of the price gap varied between $40 \%-52.6 \%$. The lowest was IgG and IgM test, and the highest was antal thrombocyte test.

Micro-costing approach was used to calculate the unit cost of services, due to its detailed and precise result. However, in order to use this method, a large data is needed. This is very challenging due to Indonesia's situation, where the database may not provide the primary data needed.

In this study, some efforts had been done to gather the primary and even secondary data to complete the calculation. To gather such a large data set some interviews to the hospital staff and manual measurement were done. Data of material consumed, time spent in labor, and time usage of the equipment were gathered from each service's standard operating procedure and direct measurement, while the output of each service (in this case, the number of patient that received the service was used) were gathered from the hospital database and laboratory logbook. A good communication 
and cooperation amongst internal staffs were needed. Knowledge about the importance of cost analysis study for the hospital would improve cooperation from the staffs.

The unit cost result of each laboratory services varied because it depended on the quantity of resources consumed and the quantity of the output. The higher the resources consumed to provide a service, the higher the cost would be. However, the higher the quantity of the output, the lower the cost would be.

The unit cost calculation was set up to be provider prospective because it aimed to evaluate the reimbursement rate setting, which was under the regulation of local government. Since there is no guidance to calculate the unit cost of services in Indonesia, the cost calculation followed the standard unit cost method as mentioned in WHO guidance and other hospital cost manual, which included capital, material and labor cost.

The costing template was developed using Microsoft Excel because Microsoft Excel is popular in Indonesia and easy to manage, even some functions that used in developing the template needs a special training, since it employs some advanced calculation. Microsoft Excel can provide a precise data and suitable for developing hospital costing template as mentioned in another study about reimbursement-rate setting of hospital pharmaceutical services in Thailand (Riewpaiboon \& Kumluang, 2011).

Hospital departments were categorized into transient and absorbing cost centres because in order to allocate the cost. Since the bottom-up approach was used, every department that could obtain revenue from patients was categorized into absorbing cost centre. Hospital departments that support other departments was categorized into transient cost centre.

When compared to the reference price, there was a variable difference between unit costs of laboratory services, ranging from 40-52.6\%, which indicated that the existing reference price was not relevant with the actual cost. This might happen because the reference price set by the government did not consider all cost objects, while the micro-costing method did. Micro-costing method calculated the unit cost by including the capital, material, and labor cost that were able to be traced in order to check the calculation, while the reference price might be calculated by including only material cost, since public hospitals tend to neglect its capital and labor cost.

Another factor that affected unit cost is the output. The higher the output, the lower the unit cost would be. Pratama Yogyakarta Hospital is a new district hospital built in 2016 that was developed from a public health centre (Puskesmas). During the period of financial data collection, the output or number of the tests received by patients was very low. Since the indirect cost were distributed equally to each output, low number on the lab test caused high indirect cost, which would increase unit cost. The difference might not be this high if only the direct cost was calculated to determine the unit cost. The indirect cost calculation might be useful for private hospitals since they have to be very careful to calculate the unit cost to obtain revenue from patients. Hospitals can use the referral system to increase output by promoting the hospital to the public health centres nearby. It is a real challenge for the hospital to provide excellent service and increase efficiency while minimizing cost (Younis, Jabr, Plante, \& Forgione, 2013).

Different method and approach used to calculate the unit cost will affect the result (Riewpaiboon et al., 2007). Recently, capital cost is calculated using economic approach. Inflation adjustment factor is employed to the calculation, since it should not be neglected. However, in Indonesia government's financial system the inflation adjustment factor is not employed in the cost calculation. However, in this study, the cost calculation employed was standard costing method while it might not be the case for the reference price. There was no clear information about the cost object and cost items that employed in the reference price that was set by the government of Yogyakarta City through Yogyakarta Major Decree number 18 in 2016.

The reference price was set while considering the average price of laboratory services in some hospitals in Yogyakarta; it was not calculated using the standard costing method to estimate the unit cost of each service. 
In addition, according to the budgeting system, public hospitals received financial support from the government, hence the price may not reflect the actual cost. However, this study aimed to obtain new insights in hospital unit cost calculation. Another method that possible to do and easier to complete the data is ratio cost to charge (RCC) method. There should be a study to compare the unit cost result using different methods to give a comparable result so the government and health care providers can choose the most suitable method to calculate the unit cost of medical services. There must be a clear guidance to calculate the unit cost based on the standard costing method and agreed by both health care providers and the government.

\section{Conclusions}

The micro-costing method could be considered as a method to calculate the unit cost of medical services in Indonesian hospitals. However, the unit cost depends on the quantity of resources consumed and the quantity of outputs. Numerous data was required to calculate the unit cost, which is labor-intensive. Good communication and awareness amongst hospital staffs had been a significant support to the study.

\section{Acknowledgements}

This study was completed with supports from LPDP (Indonesia Endowment Fund for Education), Pratama Yogyakarta Hospital and Health District Office of Yogyakarta City.

\section{References}

Cao, P., Toyabe, S., \& Akazawa, K., 2006. Development of a Practical Costing Method for Hospitals. Tohoku J Exp Med, 208(3), pp. 213-224.

Cao, P., Toyabe, S., Kurashima, S., Okada, M., \& Akazawa, K., 2006. A Modified Method of Activity-Based Costing For Objectively Reducing Cost Drivers in Hospitals. Methods Inf Med, 45(4), pp. 462-469.
Chatterjee, S., Levin, C., \& Laxminarayan, R., 2013. Unit Cost of Medical Services at Different Hospitals in India. PLoS One, 8(7), pp. e69728.

Javid, M., Hadian, M., Ghaderi, H., Ghaffari, S., \& Salehi, M., 2015. Application of the ActivityBased Costing Method for Unit-Cost Calculation in a Hospital. Glob J Health Sci, 8(1), pp. 165-172.

Kementerian Kesehatan Republik Indonesia., 2016. Standar Tarif Pelayanan Kesehatan dalam Penyelenggaraan Program Jaminan Kesehatan. Jakarta: Ministry of Health.

Riewpaiboon, A., \& Kumluang, S., 2011. Cost Analysis for Reimbursement-Rate Setting of Hospital Pharmaceutical Services in Thailand. Int J Pharm Pract, 19(5), pp. 333341.

Riewpaiboon, A., Malaroje, S., \& Kongsawatt, S., 2007. Effect of Costing Methods on Unit Cost of Hospital Medical Services. Trop Med Int Health, 12(4), pp. 554-563.

Schulman-Marcus, J., Prabhakaran, D., \& Gaziano, T.A., 2010. Pre-hospital ECG for Acute Coronary Syndrome in Urban India: a CostEffectiveness Analysis. BMC Cardiovasc Disord, 10, pp.13.

Teerawattananon, Y., Kingkaew, P., Koopitakkajorn, T., Youngkong, S., Tritasavit, N., Srisuwan, P., \& Tantivess, S., 2016. Development of a Health Screening Package Under the Universal Health Coverage: The Role of Health Technology Assessment. Health Econ, 25 Suppl 1, pp. 162-178.

WHO., 2013. Research for Universal Health Coverage. Retrieved from Geneva.

Yereli, A.N., 2009. Activity-based Costing And Its Application in a Turkish University Hospital. Aorn j, 89(3), pp. 573-591.

Younis, M.Z., Jabr, S.F., Plante, C., \& Forgione, D.A., 2013. Estimation of Health Care Costs and Cost Recovery: the Case of Rafidya Hospital in Palestine. J Health Care Finance, 39(4), pp. 44-54. 